\title{
Anion photoelectron imaging of deprotonated thymine and cytosine
}

\author{
Bradley F. Parsons, ${ }^{a}$ Sean M. Sheehan, ${ }^{a}$ Terry A. Yen, ${ }^{a}$ Daniel M. Neumark, ${ }^{* a}$ \\ Nadine Wehres $^{b}$ and Rainer Weinkauf ${ }^{b}$
}

Received 28th February 2007, Accepted 5th April 2007

First published as an Advance Article on the web 3rd May 2007

DOI: $10.1039 / \mathbf{b} 703045 b$

\begin{abstract}
We report the anion photoelectron spectra of deprotonated thymine and cytosine at $3.496 \mathrm{eV}$ photodetachment energy using velocity-mapped imaging. The photoelectron spectra of both species exhibit bands resulting from detachment transitions between the anion ground state and the ground state of the neutral radical. Franck-Condon simulations identify the anion isomers that contribute to the observed photoelectron spectrum. For both thymine and cytosine, the photoelectron spectra are consistent with anions formed by removal of a proton from the $\mathrm{N}$ atom that normally attaches to the sugar in the nucleotide (N1). For deprotonated thymine, the photoelectron spectrum shows a band due to a ring breathing vibration excited during the photodetachment transition. The electron affinity for the dehydrogenated thymine radical is determined as $3.250 \pm 0.015 \mathrm{eV}$. For deprotonated cytosine, the photoelectron spectrum lacks any resolved structure and the electron affinity of the dehydrogenated cytosine radical is determined to be $3.037 \pm 0.015 \mathrm{eV}$. By combining the electron affinity with previously measured gas phase acidities of thymine and cytosine, we determine the bond dissociation energy for the $\mathrm{N}-\mathrm{H}$ bond that is broken.
\end{abstract}

\section{Introduction}

Deoxyribonucleic acid (DNA) is the information carrier used in most biological systems. Mutagenic changes to the nucleobase sequence may result in coding an incorrect amino acid inside a protein with potentially lethal results. Such mutagenic changes to the nucleobase sequence can result from single strand breaks (SSB) and double stand breaks (DSB) following exposure to ionizing radiation. ${ }^{1}$ Ionizing radiation results in $\sim 10^{4}$ electrons per $\mathrm{MeV}$ and these electrons undergo multiple inelastic collisions inside the cell resulting in thermalization within a few picoseconds. ${ }^{2}$ The initial step of radiation damage is trapping of these thermal electrons by a nucleobase inside DNA. Following electron attachment, lethal DNA lesions such as strand breaks may occur through cleavage of either the sugar-phosphate bond or the sugar-nucleobase bond.

A molecular level understanding of these phenomena requires knowing the energetics of the processes that low-energy electrons induce in the constituents of DNA. The focus of the work described here is on measuring photoelectron spectra of two deprotonated DNA bases, cytosine $\left(\mathrm{C}_{-\mathrm{H}}{ }^{-}\right)$and thymine $\left(\mathrm{T}_{-\mathrm{H}^{-}}{ }^{-}\right)$. These measurements yield electron affinities of the corresponding open shell radical species, and thus provide a key ingredient in understanding one of the most fundamental electron-induced processes, dissociative electron attachment

\footnotetext{
${ }^{a}$ Department of Chemistry, University of California, Berkeley, CA 94720, and Chemical Sciences Division, Lawrence Berkeley National Laboratory, Berkeley, CA 94720, USA. E-mail: dneumark@berkeley.edu

${ }^{b}$ Institut für Physikalische Chemie und Elektrochemie I, HeinrichHeine Universität Düsseldorf, Gebäude26.33.O, 2.36,

Universitätsstraße 1, 40225 Düsseldorf, Germany
}

(DEA) of an isolated DNA base,

$$
\mathrm{T}+\mathrm{e}^{-} \rightarrow(\mathrm{T}-\mathrm{H})^{-}+\mathrm{H} .
$$

Comparison of low energy electron scattering experiments by Illenberger $^{3-7}$ on gas phase DNA bases and those by Sanche $^{1,8-10}$ on self-assembled monolayer films of DNA strands have implicated DEA as the primary mechanism for SSB's in DNA. In gas phase studies of thymine, the ion yield from reaction (1) as a function of incident electron energy is dominated by a sharp peak at $1 \mathrm{eV}$ and a broader feature at $1.8 \mathrm{eV}$; these have been shown to arise from DEA at the N1 and N3 atoms, respectively (see Fig. 1a). ${ }^{6,7}$ In Sanche's experiments, the SSB yield at low electron energies is very similar, indicating that much of the same electron attachment physics in the gas phase bases is operative in full DNA strands.

Calculations by Simons ${ }^{1-15}$ have indicated that the electron forms a temporary negative ion state (TNIS) by initially occupying the empty $\pi^{*}$ orbital localized on the base. In the gas phase, the TNIS undergoes a non-adiabatic transition to a $\sigma^{*}$ orbital localized on the $\mathrm{N}-\mathrm{H}$ bond, leading to reaction (1). In full DNA strands, the corresponding process is cleavage of the $\mathrm{N}-\mathrm{C}$ bond linking the nucleobase to the ribose sugar unit. However, the dominant non-adiabatic transition occurs via a through-bond interaction to a $\sigma^{*}$ orbital localized on the $\mathrm{C}-\mathrm{O}$ bond between the sugar and phosphate groups, leading to an SSB with the negative charge localized on the phosphate group. ${ }^{8}$ In contrast, Illenberger ${ }^{4}$ has assigned the sharp peak in the DEA yield to attachment into a Feshbach resonance associated with a dipole-bound state and have argued against SSB formation via the proposed through-bond $\pi^{*} \rightarrow \sigma^{*}$ coupling mechanism.

Complementary approaches to understanding the interactions between DNA constituents and electrons are offered by 


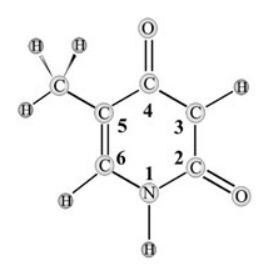

A Thymine<smiles>[2H]N1C(=O)N=C(C)C(C)C1=O</smiles>

Cytosine

B

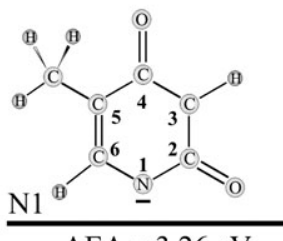

$\mathrm{AEA}=3.26 \mathrm{eV}$
N3

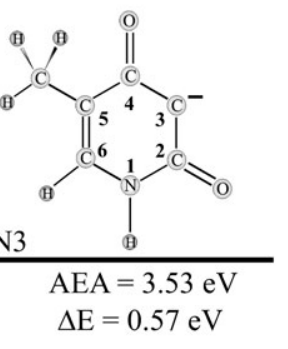<smiles>Cc1c(N(C)[O-])nc(=O)n(C)c1[N+](=O)[O-]</smiles>

C
$\mathrm{AEA}=3.03 \mathrm{eV}$ $\Delta \mathrm{E}=0.13 \mathrm{eV}$

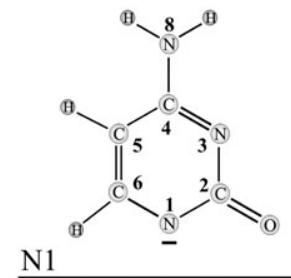

$\mathrm{AEA}=3.05 \mathrm{eV}$

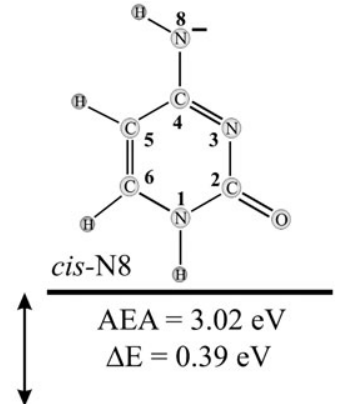

Fig. 1 (A) Structures of the canonical forms of thymine (left) and cytosine (right). The N1 position is where the nucleobase bonds to the sugar-phosphate backbone in DNA. (B) Structure and relative energy of some isomers of deprotonated thymine. The most stable isomer of deprotonated thymine is the $\mathrm{N} 1$ isomer shown on the top left in the figure. N3 deprotonated thymine is less stable by $\sim 0.57 \mathrm{eV}$. (C) Structure and relative energy of deprotonated cytosine isomers. The most stable isomer of deprotonated cytosine is the N1 isomer shown in the bottom middle of the figure. The trans-N8 isomer is less stable than the $\mathrm{N} 1$ isomer by $\sim 0.13 \mathrm{eV}$ and the $c i s-\mathrm{N} 8$ isomer is less stable than the $\mathrm{N} 1$ isomer by $\sim 0.39 \mathrm{eV}$.

Rydberg electron transfer (RET) experiments by Schermann ${ }^{16,17}$ and anion photoelectron spectroscopy (PES) carried out by Bowen ${ }^{18,19}$ and Weinkauf. ${ }^{20}$ These experiments showed that the stable anion formed by attachment of an electron to a closed-shell DNA base is a dipole-bound state, in which the excess electron is weakly bound to the highly polar base. The PE spectra yielded electron affinities in the range of 60$100 \mathrm{meV}$ and showed little or no vibrational structure, as expected for a dipole-bound state.

From the perspective of understanding dissociative electron attachment, studies of the deprotonated bases are more relevant. The corresponding neutral species are open shell radicals with substantially higher electron affinities than the closedshell bases. Calculations by Ortiz, ${ }^{21}$ Schaefer $^{22-24}$ and Mark $^{6,25}$ predict these electron affinities to lie in the range of 3-4 eV for radicals formed by $\mathrm{N}-\mathrm{H}$ bond cleavage, with considerably lower electron affinities for radicals formed by $\mathrm{C}-\mathrm{H}$ bond cleavage. These calculations illustrate one of the problems associated with spectroscopic characterization of these species, namely the existence of many close-lying struc- tural isomers of both the deprotonated anion and the openshell radical. Fig. $1 b$ and c summarize the calculated relative energetics and adiabatic electron affinities for the lowest-lying bases corresponding to removal of a proton from cytosine and thymine. The adiabatic electron affinities of both nucleobases and the relative energetics for the cytosine anion isomers are based on the work of Schaefer ${ }^{22-24}$ while the relative energetics for the thymine anion isomers are from calculations discussed in section III of this paper. All of these isomers involve deprotonation at $\mathrm{N}$ atoms and deprotonation at $\mathrm{C}$ atoms results in considerably higher energy structures. For the cytosine anion Schaefer ${ }^{22}$ calculates the most stable anion to result from deprotonation at $\mathrm{N} 1$, while $\mathrm{Ortiz}^{21}$ finds deprotonation of cytosine at N8 to give the most stable anion. Hence, binding energies obtained from PE spectra of the deprotonated anions are of limited use unless the isomer can be identified.

In this paper, we present results from our experiments on the anion photoelectron (PE) spectra for deprotonated thymine and deprotonated cytosine at $355 \mathrm{~nm}(3.496 \mathrm{eV}$ 
photodetachment energy). Section II gives a brief synopsis of the experimental setup. Section III presents the anion photoelectron spectra and describes the electronic structure calculations used to interpret the spectra. In section IV, the photoelectron spectra are analyzed via Franck-Condon simulations to determine the anion isomers that contribute to the observed spectra, based on the extent or absence of vibrational progressions. In addition, electron affinities for the radicals formed through electron detachment are determined. By combining these electron affinities with the known gas phase acidities for the canonical isomers of thymine and cytosine, we determine the bond dissociation energy for the $\mathrm{N} 1-\mathrm{H}$ bond in the neutral, closed-shell bases. Finally, the relation between the measured electron affinities and branching seen in DEA of DNA strands is discussed.

\section{Experimental setup}

The setup used for these experiments has been described in detail previously. ${ }^{26,27}$ Briefly, anions are formed by supersonically expanding 15 psig Ar carrier gas into the source region. The Ar carrier gas passes through a heated reservoir containing the nucleobase (thymine or cytosine). The reservoir is heated to $\sim 30-60{ }^{\circ} \mathrm{C}$, which is below the decomposition temperature of the nucleobase. The resulting $\mathrm{Ar} /$ nucleobase gas mixture then passes through a pulsed discharge and is crossed with a $1 \mathrm{keV}$ electron beam. Anions are then massselected using a linear reflection mass spectrometer with a mass resolution of $m / \Delta m=2000$.

Anions are photodetached using $355 \mathrm{~nm}$ photons $(3.496 \mathrm{eV})$ from the third harmonic of a pulsed Nd:YAG laser (Quanta Ray DCR-3). The laser is focused $\sim 1.5 \mathrm{~cm}$ before the interaction region using a $50 \mathrm{~cm}$ fused silica lens. Photoelectrons are collected using velocity-mapped imaging (VMI). ${ }^{28,29}$ The VMI detector is a 2-D position sensitive detector, comprising two microchannel plates coupled to a phosphor screen. A charge coupled device (CCD) records the output of the phosphor screen for later analysis. Photoelectron images are typically acquired for 50000 laser shots.

The original 3-D distribution is reconstructed from the 2-D imaging using the basis set expansion (BASEX) Abel transform method for image reconstruction. ${ }^{30}$ The photoelectron spectra of deprotonated thymine and cytosine are calibrated using the known $355 \mathrm{~nm}$ PE spectrum of $\mathrm{O}_{2}{ }^{-} \cdot{ }^{31}$ Finally, the resolution for these experiments is about 2 pixels, which corresponds to an energy resolution of $\sim 2.0 \%$.

\section{Results}

Fig. 2 (top, right) shows the velocity mapped photoelectron image of deprotonated thymine $\left(\mathrm{T}_{-\mathrm{H}}\right)^{-}$taken at a detachment energy of $3.496 \mathrm{eV}$ and Fig. 2 (top, left) shows the reconstructed image. The two bottom panels show the corresponding image and reconstruction for deprotonated cytosine $\mathrm{C}_{-\mathrm{H}^{-}}$. Fig. 3 and 4 show the anion PE spectra for $\mathrm{T}_{-\mathrm{H}^{-}}{ }^{-}$and $\mathrm{C}_{-\mathrm{H}}{ }^{-}$, respectively, derived from the reconstructed photoelectron images in Fig. 2. The PE spectra are plotted in electron binding energy (eBE), defined as eBE $=h \nu-\mathrm{eKE}$, where $h \nu$ is photon
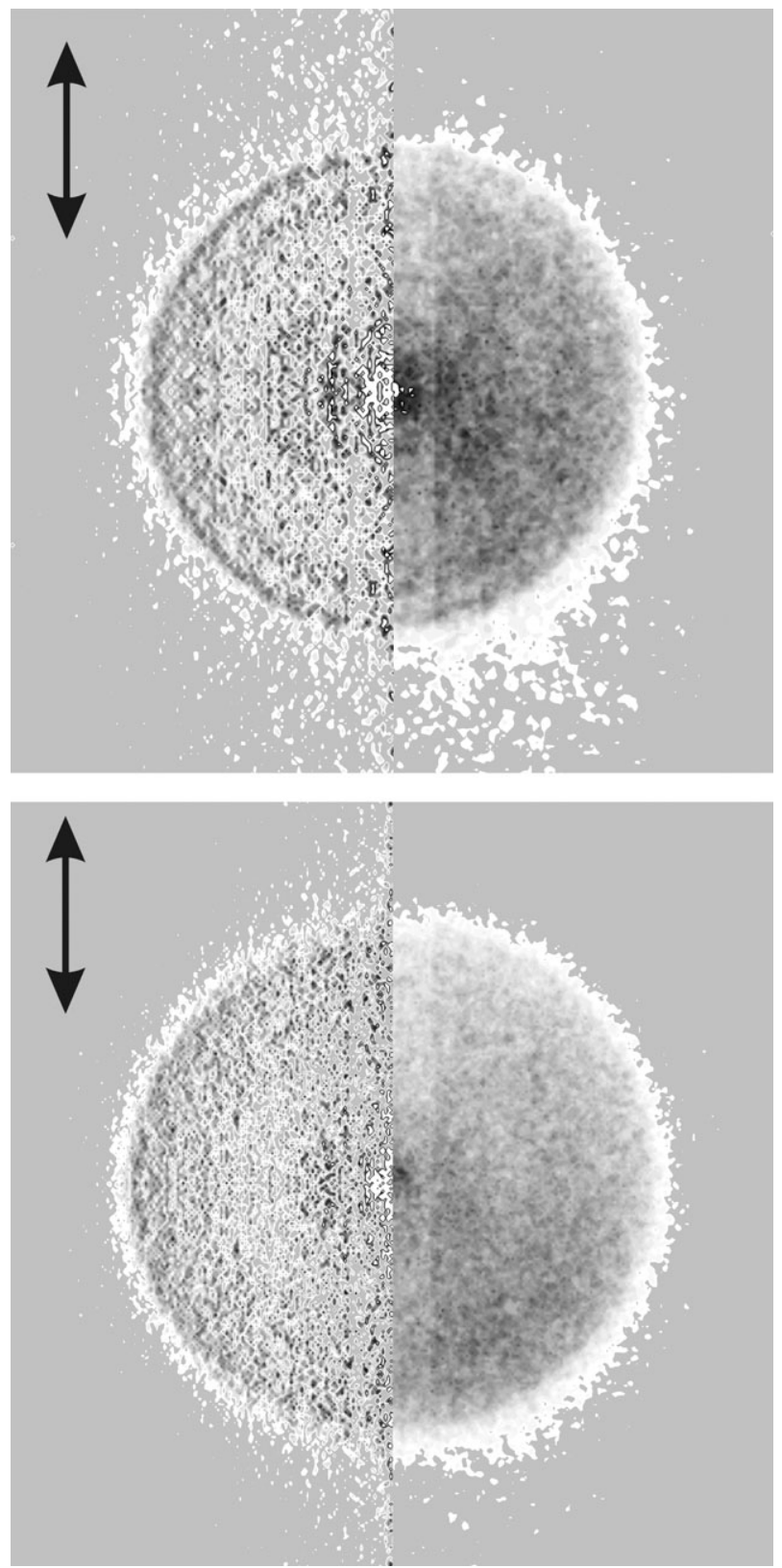

Fig. 2 Photoelectron images of deprotonated thymine (top) and deprotonated cytosine (bottom). In both images, the right side of the figure shows the raw photoelectron image at $3.496 \mathrm{eV}$ and the left side of the figure shows the transformed image. The arrow indicates the polarization vector of the laser.

energy and $\mathrm{eKE}$ is electron kinetic energy derived from the image.

The $\mathrm{T}_{-\mathrm{H}}{ }^{-} \mathrm{PE}$ spectrum shows two bands, $\mathrm{X}_{0}$ and $\mathrm{X}_{1}$, with peak maxima at 3.250 and $3.309 \mathrm{eV}$, respectively. The lower binding energy band $\mathrm{X}_{0}$ is the origin transition corresponding to detachment from the anion ground state to the ground state of the neutral radical. In the next section, a particular thymine radical is assigned to the $\mathrm{X}_{0}$ band allowing for a determination of that radicals electron affinity as about $3.250 \mathrm{eV}$. Band $\mathrm{X}_{1}$ may be from either a vibrational progression or the origin transition of a second deprotonated thymine isomer. 

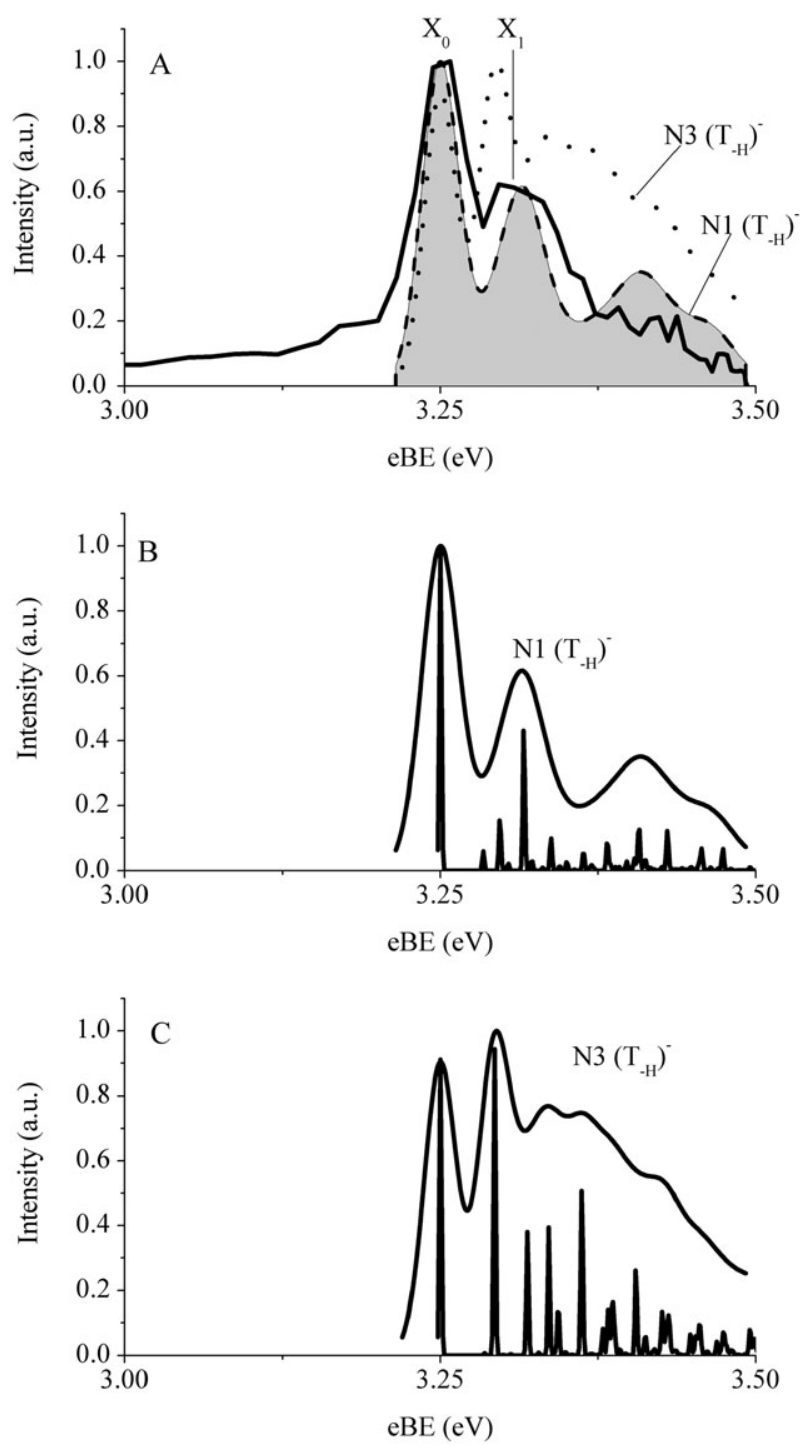

Fig. 3 Anion photoelectron spectrum of deprotonated thymine at $3.496 \mathrm{eV}$. Panel A shows the experimental photoelectron spectrum (solid black line). The dashed line in panel A shows the FC simulation for $\mathrm{N} 1 \mathrm{~T}_{-\mathrm{H}}{ }^{-}$convoluted the instrument resolution and the dotted line shows the convoluted $\mathrm{FC}$ simulation for $\mathrm{N} 3 \mathrm{~T}_{-\mathrm{H}}{ }^{-}$. Panel B shows the stick spectrum of the $\mathrm{FC}$ profile for $\mathrm{N} 1 \mathrm{~T}_{-\mathrm{H}}{ }^{-}$along with the convoluted FC profile and panel $\mathrm{C}$ shows the stick spectrum of the FC profile for $\mathrm{N} 3 \mathrm{~T}_{-\mathrm{H}}{ }^{-}$along with the convoluted $\mathrm{FC}$ profile.

Assignment of band $\mathrm{X}_{1}$ requires additional analysis, as discussed in the next section. The $\mathrm{C}_{-\mathrm{H}}{ }^{-} \mathrm{PE}$ spectrum shows a single broad feature, $\mathrm{X}_{0}$, centered around $3.05 \mathrm{eV}$. Additional analysis of the $\mathrm{X}_{0}$ band of $\mathrm{C}_{-\mathrm{H}}{ }^{-}$is given in the next section along with an assignment of the electron affinity for the cytosine radical observed in the photoelectron spectrum.

From the reconstructed photoelectron images, the photoelectron angular distribution can be determined and fit to the standard equation ${ }^{32}$

$$
I(\theta)=\frac{1}{4 \pi}\left\{1+\beta P_{2}(\cos \theta)\right\}
$$

where $I(\theta)$ is the photoelectron angular distribution, $P_{2}(\cos \theta)$ is the second Legrendre polynomial. The angle $\theta$ is between the laser electric field and the TOF axis of the electron. The anisotropy parameter is $\beta=-0.2 \pm 0.1$ for both bands in the $\mathrm{T}_{-\mathrm{H}}{ }^{-} \mathrm{PE}$ spectrum and for the only band in the $\mathrm{C}_{-\mathrm{H}}{ }^{-} \mathrm{PE}$ spectrum.

Analysis of the photoelectron spectra requires the geometries and normal modes for the anion and neutral involved in the photodetachment transition. The structures in Fig. $1 \mathrm{~b}$ and $\mathrm{c}$ were investigated using density functional theory. The calculations were performed with a non-augmented double- $\zeta$ basis set (cc-pVDZ) and the BP86 and BLYP functionals using the Gaussian 03 program. ${ }^{33}$ These are the same density functionals used previously to calculate the adiabatic electron affinities, ${ }^{22,24}$ although a smaller basis set is used in our calculations. The previous thymine calculations did not report the relative anion energetics, but our BP86/cc-pVDZ calculations for thymine show that the N1 anion is the most stable and the $\mathrm{N} 3$ anion lies $0.57 \mathrm{eV}$ above N1.

\section{Analysis and discussion}

Several deprotonated isomers can potentially contribute to the observed photoelectron spectra in Fig. 3 and 4. In the case of thymine, the $\mathrm{N} 1$ and $\mathrm{N} 3$ radicals have electron affinities in the energetic range of the photoelectron spectra and in the case of cytosine, the $\mathrm{N} 1$ and both trans- $\mathrm{N} 8$ and cis- $\mathrm{N} 8$ radicals have electron affinities consistent with the photoelectron spectra (see Fig. 1). In the case of both cytosine and thymine, the adiabatic electron affinities for the isomers corresponding to deprotonation of a carbon site are $0.5-2 \mathrm{eV}$ lower in energy relative to the experimental photoelectron spectra. Therefore, we consider only the isomers involving deprotonation at the nitrogen sites, which have calculated adiabatic electron affinities in good agreement with the photoelectron spectra. We assign which isomers contribute to the photoelectron spectra by determining the Franck-Condon (FC) profiles for anion $\rightarrow$ neutral transitions originating from each anion isomer deprotonated at nitrogen sites. The FC profiles are calculated using the MolFC program, which uses the optimized geometry and normal modes of the anion and neutral from BLYP/cc-pVDZ calculations as described above. MolFC ${ }^{34}$ calculates the FC factors for selected active vibrational modes of the anion and neutral. The Duschinsky transformation is used to determine the rotation matrix $\boldsymbol{J}$ and the displacement vector $\boldsymbol{K}$ between the normal modes of the anion and neutral. FC factors can then be calculated using a series of recursion relations. The FC factors from MolFC are convoluted with an instrument resolution function to generate the predicted photoelectron spectrum for the individual isomers of deprotonated thymine or cytosine. A comparison of the convoluted FC simulation with a resolution of $25 \mathrm{meV}$ with the photoelectron spectrum allows for an assignment of the deprotonated anion that is formed in the experiment.

We first consider the anion photoelectron spectrum for deprotonated thymine. Fig. 3a compares the experimental spectrum to the convoluted FC simulation for both the N1 (dashed line) and N3 (dotted line) anions of deprotonated thymine. The two lower panels show stick spectra of the FC profile for each detachment transition. Since the electron affinity for neither the N1 nor N3 radical is known 

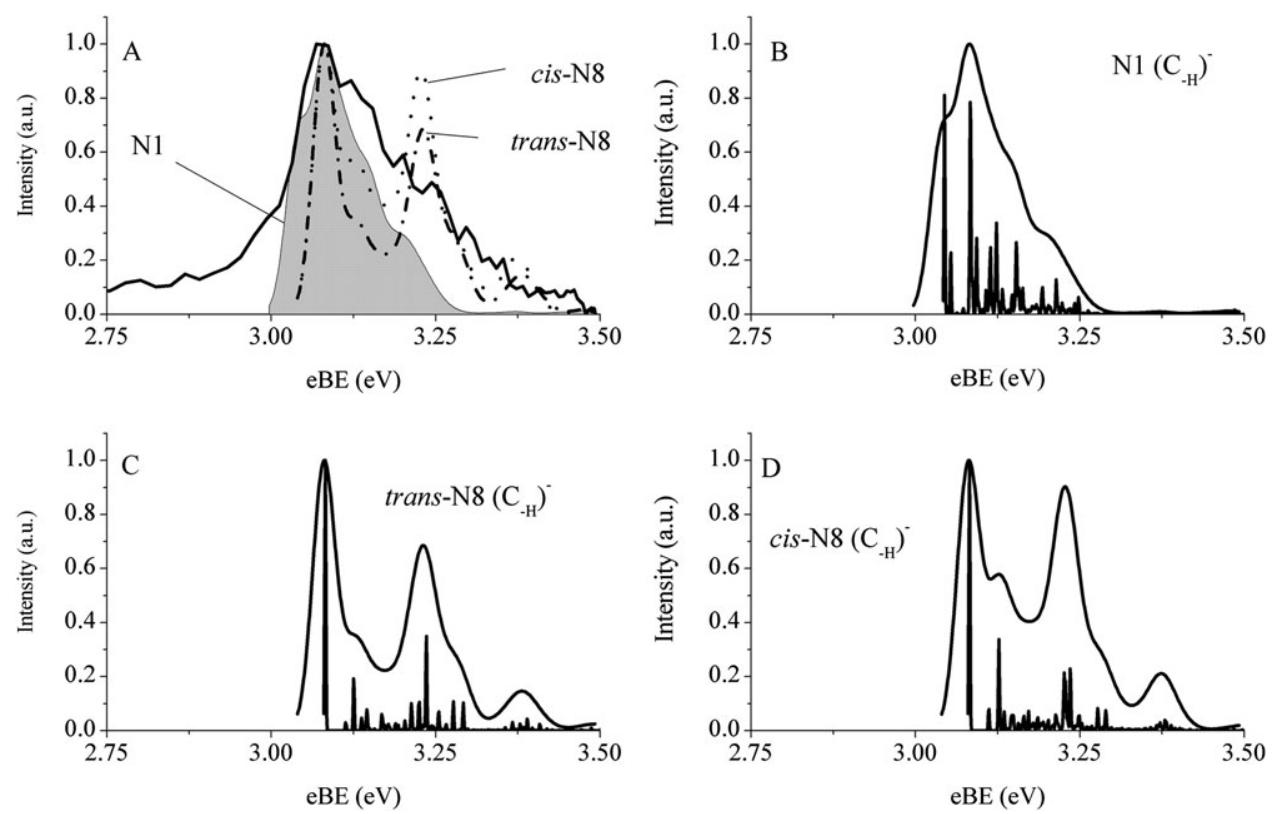

Fig. 4 Anion photoelectron spectrum of deprotonated cytosine at $3.496 \mathrm{eV}$. Panel A shows the experimental photoelectron spectrum (solid black

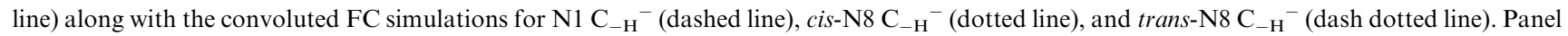

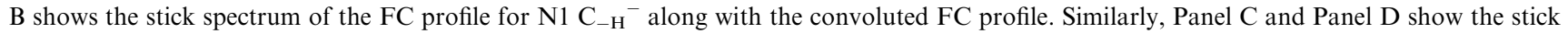
spectrum and convoluted $\mathrm{FC}$ profile for trans- $\mathrm{N} 8 \mathrm{C}_{-\mathrm{H}^{-}}{ }^{-}$and $c i s-\mathrm{N} 8 \mathrm{C}_{-\mathrm{H}^{-}}{ }^{-}$, respectively.

experimentally, the peak at lowest binding energy in the convoluted FC simulation is overlapped with band $\mathrm{X}_{0}$ in the photoelectron spectrum.

According to the FC simulation for $\mathrm{N} \mathrm{T}_{-\mathrm{H}}{ }^{-}$(Fig. 3b), the most intense feature in the photoelectron spectrum is the transition from the vibrational ground of the anion to the vibrational ground state of the neutral. Furthermore, the N1 FC simulation shows activity in a ring deformation mode $\left(\nu_{9}\right)$ with a vibrational frequency of $534 \mathrm{~cm}^{-1}$. Deprotonation at the $\mathrm{N} 1$ site results in a lone pair of electrons in the former $\sigma(\mathrm{N} 1-\mathrm{H})$ bonding orbital. Removal of one of these electrons to make the radical leads to a small distortion of the sixmember thymine ring and activity in the $\nu_{9}$ mode. The FC simulation for $\mathrm{N} 1 \mathrm{~T}_{-\mathrm{H}^{-}}$predicts bands consistent with the intensity and binding energy for both bands $\mathrm{X}_{0}$ and $\mathrm{X}_{1}$ in the photoelectron spectrum, although the weak simulated feature at $3.4 \mathrm{eV}$ is not evident in the experimental spectrum.

The FC simulation for $\mathrm{N}^{3} \mathrm{~T}_{-\mathrm{H}^{-}}{ }^{-}$(Fig. 3c) is significantly different from the N1 FC simulation. The most intense band in the simulated photoelectron spectrum corresponds to the first excited vibrational level of $\nu_{6}$ with a frequency of $347 \mathrm{~cm}^{-1}$. This mode corresponds to a concerted bend of the $\mathrm{O}=\mathrm{C}(4)-\mathrm{N}(3)-\mathrm{C}(2)=\mathrm{O}$ portion of the thymine skeleton. The N3 isomer exhibits significant activity in $\nu_{6}$ because the lone pair of electrons created by deprotonation is localized in the former $\sigma(\mathrm{N} 3-\mathrm{H})$ bonding orbital, where the lone pair can interact with the two adjacent $\mathrm{C}=\mathrm{O}$ groups. Detachment of one electron from this orbital results in significant shortening of the two $\mathrm{C}-\mathrm{N}_{3}$ bonds in the ring, leading to the observed vibrational activity in $\nu_{6}$. The $\mathrm{FC}$ simulation for $\mathrm{N} 3 \mathrm{~T}_{-\mathrm{H}^{-}}{ }^{-}$ predicts a band near $3.29 \mathrm{eV}$ eBE, which is $25 \mathrm{meV}$ lower in energy than band $X_{1}$ in the experimental photoelectron spectrum (Fig. 3A). Furthermore, the intensity of the $3.29 \mathrm{eV}$ band in the N3 simulation does not agree with band $X_{1}$. It thus appears that $\mathrm{N} 3 \mathrm{~T}_{-\mathrm{H}}{ }^{-}$does not contribute significantly to the observed photoelectron spectrum.

On the basis of comparison between the experimental and simulated spectra, we assign the photoelectron spectrum in Fig. $3 \mathrm{~A}$ as resulting from photodetachment of $\mathrm{N} 1 \mathrm{~T}_{-\mathrm{H}^{-}}{ }^{-}$. From the lowest energy transition in the photoelectron spectrum, the electron affinity for the N1 thymine radical is determined to be $3.250 \pm 0.015 \mathrm{eV}$, in good agreement with the calculated electron affinity ${ }^{22}$ for the $\mathrm{N} 1$ radical, $3.26 \mathrm{eV}$.

Next, we consider the photoelectron spectrum of deprotonated cytosine. Fig. 4a shows the $\mathrm{C}_{-\mathrm{H}}{ }^{-}$photoelectron spectrum along with FC simulations for N1 (dashed line), cis-N8 (dotted line), and trans-N8 (dash dotted line) $\mathrm{C}_{-\mathrm{H}^{-}}{ }^{-}$. The simulated photoelectron spectrum (Fig. 4b) for $\mathrm{N} 1 \mathrm{C}_{-\mathrm{H}}{ }^{-}$ has very little structure after convolution with the instrument resolution. The stick spectrum for $\mathrm{N} 1 \mathrm{C}_{-\mathrm{H}}{ }^{-}$shows activity in the $\nu_{4}$ vibrational mode with a frequency of $319 \mathrm{~cm}^{-1}$, corresponding to $\mathrm{NH}_{2}$ umbrella motion. Activity in this mode results because the $\mathrm{NH}_{2}$ group becomes more planar with respect to the six-member ring upon photodetachment, with the dihedral angle dropping from 42.6 to $19.8^{\circ}$. This change, in turn, reflects the shorter $\mathrm{C}-\mathrm{N} 8$ bond length in the radical, 1.37 $\AA$ vs. $1.43 \AA$; the shorter bond has more double-bond character, resulting in a nearly planar $\mathrm{C}-\mathrm{NH}_{2}$ group. The FC simulation also shows a low intensity peak, $\nu_{7}$ at $510 \mathrm{~cm}^{-1}$, that has $\mathrm{C}-\mathrm{N}$ (amine) stretching character.

The FC simulations for both trans-N8 (Fig. 4c) and cis-N8 (Fig. 4d) $\mathrm{C}_{-\mathrm{H}^{-}}{ }^{-}$are qualitatively similar and are therefore discussed together. The FC simulations for both radicals display activity in a low frequency $\left(\nu_{4}\right)$ mode that corresponds to $\mathrm{N}(8)-\mathrm{C}-\mathrm{C}$ bending motion with a frequency of $350 \mathrm{~cm}^{-1}$ (trans-N8) and of $362 \mathrm{~cm}^{-1}$ (cis-N8). Furthermore, the 
simulations show activity in the $\nu_{21}$ vibrational mode, which results from a $\mathrm{H}-\mathrm{N}(8)-\mathrm{C}$ bending mode of either radical. The frequency of the $\nu_{21}$ vibrational mode is $1240 \mathrm{~cm}^{-1}$ (trans-N8) and $1237 \mathrm{~cm}^{-1}$ (cis-N8). Activity in $\nu_{3}$ and $\nu_{21}$ arises because deprotonation of the $\mathrm{NH}_{2}$ group results in a lone electron pair that is localized in the former $\sigma(\mathrm{N} 8-\mathrm{H})$ bonding orbital. This large lone electron pair distorts the geometry of the amine group in the anion relative to the radical.

The FC simulations for trans-N8 and cis- $\mathrm{N} 8 \mathrm{C}_{-\mathrm{H}}{ }^{-}$do not reproduce the experimental photoelectron spectrum. In particular, both FC simulations predict an intense band near $3.2 \mathrm{eV}$ binding energy. The predicted band at $3.2 \mathrm{eV}$ is far from the origin transition at $3.0 \mathrm{eV}$ and consequently such an intense band would be easily resolved by the photoelectron imaging experiments. Since the photoelectron spectrum shows no evidence of such a band near $3.2 \mathrm{eV}$ neither $\mathrm{N} 8$ isomer of $\mathrm{C}_{-\mathrm{H}}{ }^{-}$appears to contribute significantly to the observed spectrum in Fig. 4 a.

As already discussed, the $\mathrm{FC}$ simulation for $\mathrm{N} 1 \mathrm{C}_{-\mathrm{H}}{ }^{-}$shows a single broad feature. Taking the electron affinity of the N1 cytosine radical as $3.037 \pm 0.015 \mathrm{eV}$ for the $\mathrm{N} 1$ cytosine radical, the $\mathrm{N} 1 \mathrm{FC}$ simulation provides a reasonable fit to the photoelectron spectrum is shown in Fig. 4a. This electron affinity is in good agreement with previous calculations. ${ }^{24}$ Finally, an attempt to fit the photoelectron spectrum as a linear combination of $\mathrm{N} 1$, trans- $\mathrm{N} 8$, and $c i s-\mathrm{N} 8 \mathrm{C}_{-\mathrm{H}}{ }^{-}$resulted in a simulated spectrum that is too narrow to fit the band observed in the experiment.

The electron affinity for the dehydrogenated radicals can be used to determine the bond enthalpy for the $\mathrm{N}-\mathrm{H}$ bond broken during formation of the radical. The bond enthalpy is related to the electron affinity by:

$$
\Delta H=\mathrm{GPA}-\mathrm{IP}(\mathrm{H})+\mathrm{EA}
$$

where $\Delta H$ is the bond enthalpy, GPA is the gas phase acidity for the $\mathrm{N}-\mathrm{H}$ bond, $\mathrm{IP}(\mathrm{H})$ is the ionization energy of atomic hydrogen, and EA is the electron affinity of the dehydrogenated radical. The ionization energy of hydrogen is well known and our experiment directly measures the electron affinity of the radical. The gas phase acidity for thymine ${ }^{35}$ and cytosine ${ }^{36}$ has been measured by Lee using bracketing experiments. Lee gives the GPA for thymine as $14.49 \pm 0.11$ $\mathrm{eV}$ and the GPA for cytosine as $14.79 \pm 0.10 \mathrm{eV}$. The GPA is measured with the nucleobase thermalized at $298 \mathrm{~K}$. Therefore, we account for the heat capacities of all species to determine the $298 \mathrm{~K}$ bond enthalpy. Inserting the GPA, electron affinity and ionization potential of atomic hydrogen into the above equation, we determine the bond enthalpy for thymine as $\Delta H(\mathrm{~T}, \mathrm{~N}-\mathrm{H})=3.97 \pm 0.11 \mathrm{eV}$ and for cytosine as $\Delta H(\mathrm{C}, \mathrm{N}-\mathrm{H})=3.98 \pm 0.12 \mathrm{eV}$. Previous work ${ }^{5}$ has assumed bond enthalpies for these nucleobases in the range of $4.0-4.3 \mathrm{eV}$.

Sanche ${ }^{8,9}$ has shown that cleavage of the sugar-phosphate bond is the major dissociation pathway following electron attachment to oligomeric tetramers (CGTA and GCAT). However, cleavage of the nucleobase-sugar bond was also observed as a minor pathway. Furthermore, the propensity for nucleobase-sugar bond cleavage was determined to be $\mathrm{T}>$ A $>$ C $>$ G. Nucleobase-sugar bond cleavage leads to formation of the N1 anion for both thymine and cytosine. In the model proposed by Simons, ${ }^{11}$ the electron affinities of the moieties produced by DEA play a key role in determining the observed branching. The electron affinities for the N1 anions of thymine and cytosine are $\mathrm{EA}\left(\mathrm{T}_{-\mathrm{H}}\right)=3.250 \pm$ $0.015 \mathrm{eV}$ and $\mathrm{EA}\left(\mathrm{C}_{-\mathrm{H}}\right)=3.037 \pm 0.015 \mathrm{eV}$ indicating the $\mathrm{N} 1$ thymine anion is more stable than the N1 cytosine anion, which is consistent with the trends seen in Sanche's experiments.

\section{Conclusion}

In this paper, we present the $3.496 \mathrm{eV}$ photoelectron spectra of deprotonated thymine and cytosine obtained using velocity mapped photoelectron imaging. The photoelectron spectrum of deprotonated thymine exhibits two bands and the FC simulation for the $\mathrm{N} 1$ thymine anion successfully reproduces the bands observed in the spectrum. Furthermore, the experimental electron affinity of the dehydrogenated N1 radical is in good agreement with Schaefer's calculations. For deprotonated cytosine, the photoelectron spectrum shows only a single band, which is best fit by the FC simulation by N1 deprotonated cytosine. The electron affinity of the dehydrogenated N1 radical of cytosine is consistent with previous calculations. The experimental electron affinity for N1 dehydrogenated thymine or cytosine is combined with previous gas phase acidity measurements to determine the $\mathrm{N}_{1}-\mathrm{H}$ bond enthalpy. Finally, electron affinities determined from the current experiments are consistent with Sanche's measurements of the relative propensities for sugar-nucleobase bond cleavage in single strand DNA.

\section{Acknowledgements}

We gratefully acknowledge the financial support of the National Science Foundation under grant number DMR0139064. Furthermore we would like to thank Heinrich Hertz Stiftung for grant number B $41 \mathrm{Nr} .11 / 04$.

\section{References}

1 B. Boudaiffa, P. Cloutier, D. Hunting, M. A. Huels and L. Sanche, Science, 2000, 287, 1658.

2 S. M. Pimblott, J. A. LaVerne, A. Mozumder and N. J. B. Green, J. Phys. Chem., 1990, 94, 488.

3 H. Abdoul-Carime, J. Langer, M. A. Huels and E. Illenberger, Eur. Phys. J. D, 2005, 35, 399.

4 S. Ptasinska, S. Denifl, V. Grill, T. D. Mark, E. Illenberger and P. Scheier, Phys. Rev. Lett., 2005, 95, 093201.

5 S. Gohlke, H. Abdoul-Carime and E. Illenberger, Chem. Phys. Lett., 2003, 380, 595.

6 S. Ptasinska, S. Denifl, B. Mroz, M. Probst, V. Grill, E. Illenberger, P. Scheier and T. D. Mark, J. Chem. Phys., 2005, 123, 124302.

7 S. Ptasinska, S. Denifl, P. Scheier, E. Illenberger and T. D. Mark, Angew. Chem., 2005, 44, 6941.

8 Y. Zheng, P. Cloutier, D. J. Hunting, L. Sanche and J. R. Wagner, J. Am. Chem. Soc., 2005, 127, 16592.

9 Y. Zheng, P. Cloutier, D. J. Hunting, J. R. Wagner and L. Sanche, J. Chem. Phys., 2006, 124, 064710.

10 F. Martin, P. D. Burrow, Z. Cai, P. Cloutier, D. Hunting and L. Sanche, Phys. Rev. Lett., 2004, 93, 068101.

11 J. Simons, Acc. Chem. Res., 2006, 39, 772.

12 J. Berdys, I. Anusiewicz, P. Skurski and J. Simons, J. Am. Chem. Soc., 2004, 126, 6441. 
13 J. Berdys, I. Anusiewicz, P. Skurski and J. Simons, J. Phys. Chem. A, 2004, 108, 2999.

14 J. Berdys, P. Skurski and J. Simons, J. Phys. Chem. A, 2004, 108, 5800.

15 R. Barrios, P. Skurski and J. Simons, J. Phys. Chem. B, 2002, 106, 7991.

16 C. Desfancois, H. Abdoul-Carime and J. P. Schermann, J. Chem. Phys., 1996, 104, 7792.

17 C. Desfancois, V. Periquet, Y. Bouteiller and J. P. Schermann, J. Phys. Chem. A, 1998, 102, 1274.

18 J. H. Hendricks, S. A. Lyapustina, H. L. de Clercq and K. H. Bowen, J. Chem. Phys., 1998, 108, 8.

19 J. H. Hendricks, S. A. Lyapustina, H. L. de Clercq, J. T. Snodgrass and K. H. Bowen, J. Chem. Phys., 1996, 104, 7788.

20 J. Scheidt, R. Weinkauf, D. M. Neumark and E. W. Schlag, Chem. Phys., 1998, 239, 511-524.

21 M.-V. Vazquez, A. Martinez, O. Dolgounitcheva and J. V. Ortiz, J. Phys. Chem. A, 2006, 110, 11174.

22 Q. Lou, J. Li, Q. S. Li, S. Kim, S. E. Wheeler, Y. Xie and H. F. Schaefer, III, Phys. Chem. Chem. Phys., 2005, 7, 861.

23 H. F. Schaefer, III, private communication.

24 L. T. M. Profeta, J. D. Larkin and H. F. Schaefer, III, Mol. Phys., 2003, 101, 3277.

25 S. Denifl, S. Ptasinska, M. Probst, J. Hrusak, P. Scheier and T. D. Mark, J. Phys. Chem. A, 2004, 108, 6562.

26 S. M. Sheehan, G. Meloni, B. F. Parsons, N. Wehres and D. M. Neumark, J. Chem. Phys., 2006, 124, 064303.

27 B. F. Parsons, S. M. Sheehan, K. E. Kautzman, T. A. Yen and D. M. Neumark, J. Chem. Phys., 2006, 125, 244301

28 D. W. Chandler and P. L. Houston, J. Chem. Phys., 1987, 87, 1445.
29 A. T. J. B. Eppink and D. H. Parker, Rev. Sci. Instrum., 1997, 68, 3447.

30 V. Dribinski, A. Ossadtchi, V. A. Mandelshtam and H. Reisler, Rev. Sci. Instrum., 2002, 73, 2634.

31 K. M. Ervin, I. Anusiewicz, P. Skurski, J. Simons and W. C. Lineberger, J. Phys. Chem. A, 2003, 107, 8521.

32 J. Cooper and R. N. Zare, J. Chem. Phys., 1968, 48, 942.

33 M. J. Frisch, G. W. Trucks, H. B. Schlegel, G. E. Scuseria, M. A. Robb, J. R. Cheeseman, J. J. Montgomery, J. A, T. Vreven, K. N. Kudin, J. C. Burant, J. M. Millam, S. S. Iyengar, J. Tomasi, V. Barone, B. Mennucci, M. Cossi, G. Scalmani, N. Rega, G. A. Petersson, H. Nakatsuji, M. Hada, M. Ehara, K. Toyota, R. Fukuda, J. Hasegawa, M. Ishida, T. Nakajima, Y. Honda, O. Kitao, H. Nakai, M. Klene, X. Li, J. E. Knox, H. P. Hratchian, J. B. Cross, C. Adamo, J. Jaramillo, R. Gomperts, R. E. Stratmann, O. Yazyev, A. J. Austin, R. Cammi, C. Pomelli, J. W. Ochterski, P. Y. Ayala, K. Morokuma, G. A. Voth, P. Salvador, J. J. Dannenberg, V. G. Zakrzewski, S. Dapprich, A. D. Daniels, M. C. Strain, O. Farkas, D. K. Malick, A. D. Rabuck, K. Raghavachari, J. B. Foresman, J. V. Ortiz, Q. Cui, A. G. Baboul, S. Clifford, J. Cioslowski, B. B. Stefanov, G. Liu, A. Liashenko, P. Piskorz, I. Komaromi, R. L. Martin, D. J. Fox, T. Keith, M. A. Al-Laham, C. Y. Peng, A. Nanayakkara, M. Challacombe, P. M. W. Gill, B. Johnson, W. Chen, M. W. Wong, C. Gonzalez and J. A. Pople, GAUSSIAN 03, (Revision C.02), Gaussian, Inc., Wallingford, CT, 2004.

34 R. Borrelli and A. Peluso, J. Chem. Phys., 2003, 119, 8437.

35 S. Sharma, Y. Fu, D. Cardoso and J. K. Lee, private communication.

$36 \mathrm{~T}$. Li and J. K. Lee, private communication. 